treatment of diabetes on the development and progression of long-term complications in insulin-dependent diabetes mellitus. N. Engl. J. Med. 329:977-986

5. The Diabetes Control and Complications Trial/ Epidemiology of Diabetes Interventions and Complications (DCCT/EDIC) Study Research Group. 2005. Intensive diabetes treatment and cardiovascular disease in patients with type 1 diabetes. N. Engl. J. Med. 353:2643-2653.

6. Cryer, P.E. 2001. The prevention and correction of hypoglycemia. In Handbook of physiology: a critical, comprehensive presentation of physiological knowledge and concepts. Section 7, The endocrine system. Volume 2, The endocrine pancreas and regulation of metabolism. L.S. Jefferson and A.D. Cherrington, editors. Oxford University Press. New York, New York, USA. 1057-1092.

7. Dagogo-Jack, S.E., Craft, S., and Cryer, P.E. 1993. Hypoglycemia-associated autonomic failure in insulin-dependent diabetes mellitus: recent ante- cedent hypoglycemia reduces autonomic responses to, symptoms of, and defense against subsequent hypoglycemia. J. Clin. Invest. 91:819-828.

8. Segel, S.A., Paramore, D.S., and Cryer, P.E. 2002 Hypoglycemia-associated autonomic failure in advanced type 2 diabetes. Diabetes. 51:724-733.

9. Raju, B., and Cryer, P.E. 2005. Loss of the decrement in intraislet insulin plausibly explains loss of the glucagon response to hypoglycemia in insulindeficient diabetes. Diabetes. 54:757-764.

10. Gosmanov, N.R., et al. 2005. Role of the decrement in intraislet insulin for the glucagon response to hypoglycemia in humans. Diabetes Care. 28:1124-1131.

11. Israelian, Z., et al. 2005. Increasing the decrement in insulin secretion improves glucagon responses to hypoglycemia in advanced type 2 diabetes. Diabetes Care. 28:2691-2696.

12. DeRosa, M.A., and Cryer, P.E. 2004. Hypoglycemia and the sympathoadrenal system: neurogenic symptoms are largely the result of sympathetic neural, rather than adrenomedullary, activation.
Am. J. Physiol. Endocrinol. Metab. 287:E32-E41.

13. Cryer, P.E., Davis, S.N., and Shamoon, H. 2003. Hypoglycemia in diabetes. Diabetes Care. 26:1902-1912.

14. Teves, D., Videen, T.O., Cryer, P.E., and Powers, W.J. 2004. Activation of human medial prefrontal cortex during autonomic responses to hypoglycemia. Proc. Natl. Acad. Sci. U. S. A. 101:6217-6221.

15. Goldberg, P.A., et al. 2006. Antecedent hypercortisolemia is not primarily responsible for generating hypoglycemia-associated autonomic failure. Diabetes. 55:1121-1126.

16. Mason, G.F., Petersen, K.F., Lebon, V., Rothman, D.L., and Shulman, G.I. 2006. Increased brain monocarboxylic acid transport and utilization in type 1 diabetes. Diabetes. 55:929-934.

17. Kang, L., et al. 2006. Glucokinase is a critical regulator of ventromedial hypothalamic neuronal glucosensing. Diabetes. 55:412-420.

18. Choi, I.-Y., Seaquist, E.R., and Gruetter, R. 2003. Effect of hypoglycemia on brain glycogen metabolism in vivo. J. Neurosci. Res. 72:25-32.

\title{
IPEX and the role of FOXP3 in the development and function of human Tregs
}

\author{
Séverine Le Bras and Raif S. Geha
}

Division of Immunology, Children's Hospital, and Department of Pediatrics, Harvard Medical School, Boston, Massachusetts, USA.

\begin{abstract}
Genetic defects in the transcription factor forkhead box protein P3 (FOXP3) cause immune dysregulation, polyendocrinopathy, enteropathy, $X$-linked (IPEX). IPEX is thought to be due to a defect in naturally arising $\mathrm{CD4}^{+}$Tregs. In this issue of the JCI, Bacchetta and colleagues demonstrate that patients with IPEX and missense mutations in FOXP3 provide insight into the role of various domains of FOXP3 in the development and function of Tregs (see the related article beginning on page 1713).
\end{abstract}

In the past decade, naturally arising $\mathrm{CD} 4^{+} \mathrm{CD} 25^{+}$Tregs have emerged as being critical for the maintenance of peripheral immunological tolerance (1). Neonatal thymectomy in mice and thymic hypoplasia in humans (DiGeorge syndrome) result in impaired Treg generation and in the development of organ-specific autoimmune diseases $(2,3)$. Treg generation in the thymus requires interaction with MHC class II molecules expressed by cortical epithelial cells (4). Other signals have also been implicated, including those delivered by CD28, CD40 ligand, and the cytokines TNF- $\alpha$ and TGF- $\beta$ (5). However, IL-2, which is necessary for Treg survival

Nonstandard abbreviations used: FKH, forkhead; FOXP3, forkhead box protein P3; GITR, glucocorticoidinduced TNF receptor; IPEX, immune dysregulation, polyendocrinopathy, enteropathy, X-linked.

Conflict of interest: The authors have declared that no conflict of interest exists.

Citation for this article: J. Clin. Invest. 116:1473-1475 (2006). doi:10.1172/JCI28880. in the periphery, is dispensable for their development $(6,7)$.

Tregs represent a small subset of $\mathrm{CD}^{+} \mathrm{T}$ cells (5-10\%). They express several surface markers including CD25 (the IL-2 receptor $\alpha$-chain), CTL-associated antigen 4 (CTLA4), and glucocorticoid-induced TNF receptor (GITR). However, these molecules are upregulated in naive $\mathrm{CD} 4^{+} \mathrm{CD} 25^{-} \mathrm{T}$ cells following TCR stimulation and cannot therefore serve as absolute Treg markers. Recently, several groups identified the forkhead family transcription factor forkhead box protein P3 (FOXP3) as a specific molecular marker of Tregs $(8,9)$. FOXP3 expression seems to be largely restricted to a small subset of TCR $\alpha \beta$ T cells and defines 2 pools of Tregs with suppressive activity: $\mathrm{CD} 4^{+} \mathrm{CD} 25^{\text {high }}$ cells and a minor population of $\mathrm{CD} 4{ }^{+} \mathrm{CD} 25^{\text {low }}-$ $\mathrm{T}$ cells. Thus, FOXP3 expression correlates better with suppressor activity than CD25 expression (10). Ectopic expression of Foxp3 in vitro and in vivo is sufficient to convert naive murine $\mathrm{CD}^{+} \mathrm{T}$ cells to Tregs (11).
In contrast, overexpression of FOXP3 in human $\mathrm{CD}^{+} \mathrm{CD} 25^{-} \mathrm{T}$ cells in vitro is not sufficient to generate potent suppressor activity, suggesting that additional factors are required for bona fide Treg activity (12). Foxp3 expression cannot be readily induced in murine $\mathrm{T}$ cells by stimulation in vitro. In humans, cross-linking of the TCR and CD28 stimulation, or antigen-specific stimulation, can induce $\mathrm{CD}^{+} \mathrm{CD}^{+} 5^{-} \mathrm{FOXP}^{-}$cells to become Tregs and express FOXP3 and exert suppressor function $(11,13)$. These results suggest that de novo generation of Tregs may be a natural consequence of the immune response in humans.

Tregs are anergic in vitro. They fail to proliferate and secrete IL-2 in response to TCR ligation, and they depend on IL-2 generated following activation of $\mathrm{CD} 4^{+} \mathrm{CD} 25^{-} \mathrm{T}$ cells to survive and exert their function. An in vitro assay that measures the ability of $\mathrm{CD} 4^{+} \mathrm{CD} 25^{+}$ $\mathrm{T}$ cells to suppress $\mathrm{CD} 4^{+} \mathrm{CD} 25^{-} \mathrm{T}$ cell proliferation is commonly used to assess Treg function (14). The mechanisms mediating the suppression of immune responses in vivo by Tregs are still unclear. Several studies support the involvement of contact-dependent inhibition, while others suggest that Tregs can exert their function by secreting immunosuppressive cytokines such as IL-10 or TGF- $\beta$ or by directly killing their target in a perforin-dependent manner (15). 


\section{Role of FOXP3 in the generation and function of Tregs}

Several lines of evidence demonstrate that Foxp3 is both necessary and sufficient for the development and function of $\mathrm{CD} 4^{+} \mathrm{CD} 25^{+}$Tregs in mice. Mutation of Foxp3 was identified as being responsible for an X-linked recessive inflammatory disease in Scurfy mutant mice (16). Male mice hemizygous for the mutation succumb to a $\mathrm{CD}^{+}$ T cell-mediated lymphoproliferative disease characterized by wasting and multiorgan lymphocytic infiltration $(17,18)$. Tregs are absent in Scurfy mice and in mice with disruption of the Foxp3 gene. Moreover, T cellspecific ablation of Foxp3 was sufficient to induce the full lymphoproliferative autoimmune syndrome observed in Foxp3-knockout mice. Finally, the phenotype of Scurfy mice can be rescued by introduction of a Foxp 3 transgene or by bone marrow reconstitution $(10,16)$, demonstrating the causative role of Foxp3 in disease pathogenesis. Thus, in mice, the lack of Foxp3-expressing Tregs is sufficient to break down self tolerance and induce autoimmune disease.

As in mice, human $\mathrm{CD} 4{ }^{+} \mathrm{CD} 25^{\text {high }}$ cells, which express FOXP3, act as suppressors. FOXP3 mutations underlie an X-linked autoimmune lymphoproliferative disorder in humans termed immune dysregulation, polyendocrinopathy, enteropathy, X-linked (IPEX), similar to that seen in Scurfy and Foxp3-knockout mice (19-21). To date, about 20 different mutations in FOXP3 have been described in patients suffering from IPEX. However, the correlation between FOXP3 mutations and the generation and function of Tregs has not been studied. In this issue of the JCI, Bacchetta et al. (22) analyzed Treg numbers and function in 4 IPEX patients with a variety of phenotypes that ranged from no detectable symptoms to severe disease requiring bone marrow transplantation. They concluded that $\mathrm{CD} 4{ }^{+} \mathrm{CD} 25^{+} \mathrm{T}$ cells were present in all 4 patients, including one with a mutation in the first codon (ATG) that resulted in no detectable FOXP3 protein, but that the capacity of these cells to suppress the proliferation of $\mathrm{CD} 4{ }^{+} \mathrm{CD} 25$ $T$ cells was differentially impaired depending on the type of mutation, the strength of TCR stimuli, and the genotype of effector T cells. This is in sharp contrast to Scurfy mice and Foxp3-knockout mice, which lack both detectable Foxp3 and Tregs. Bacchetta et al. defined Tregs as CD25 $5^{\text {high }}$ cells that express CTLA4 and GITR but did not analyze the presence of $\mathrm{CD}^{+} \mathrm{FOXP}^{+}$cells. However, the mean fluorescence intensity of CD25 and GITR in one patient was respectively 4and 6-fold less than that in the control, and his sorted $\mathrm{CD} 4{ }^{+} \mathrm{CD} 25^{+}$cells totally lacked suppressive activity. These findings support a critical role for FOXP3 in the generation and function of human Tregs.

\section{Correlation between FOXP3 mutations and clinical phenotype}

Analysis of the other 3 patients reported by Bacchetta et al. (22) provides potential insight into the function of discrete domains of FOXP3. A missense mutation (F373A) in the forkhead (FKH) domain of FOXP3, which did not interfere with protein expression, did not impair Treg development yet resulted in severe disease. Since this mutation interferes with the transcriptional activity of FOXP3, it suggests that the DNA-binding FKH domain is critical for Treg function but not development. Data from mice suggest that the FKH domain is essential for Treg development $(16,23)$. However, the studied mutation resulted in the absence of the FKH domain. It is possible that the missense mutant in the patient retained residual transcriptional activity sufficient for Treg development but not function. Another missense mutation $(\mathrm{F} 324 \mathrm{~L})$ in the region between the leucine zipper and FKH domains of FOXP3, which did not impede protein expression or transcriptional activity, was associated with either mild or no disease and a partial defect in the suppressive activity of freshly isolated $\mathrm{CD} 4{ }^{+} \mathrm{CD} 25^{+}$cells. The differences in the clinical presentation of 2 brothers with this mutation illustrate the well-known influence of other genes on the clinical manifestations of monogenic primary immunodeficiency diseases. The observation that $\mathrm{T}$ cell lines derived from $\mathrm{CD} 4^{+} \mathrm{CD} 25^{+}$cells of all 3 patients with missense mutations suppress the proliferation of $\mathrm{CD} 4^{+} \mathrm{CD} 25^{-} \mathrm{T}$ cells normally must be interpreted with caution and may not reflect the suppressive potential of Tregs in vivo in the patients. In fact, the finding that infusion of Tregs cures autoimmune disease in Foxp3-knockout mice suggests that defective Treg function is critical for disease development.

Despite their disparate clinical phenotypes, in all 4 IPEX patients, a defect in cytokine production was detected after TCR/CD28mediated activation of PBMCs. This finding is surprising given the fact that FOXP3 downregulates cytokine production (12, 24). Furthermore, serum levels of Th1, Th2, and inflammatory cytokines are elevated in Foxp3-deficient mice (23), suggesting ongoing cytokine production in vivo by acti- vated $T$ cells. It is possible that the decreased cytokine production by the patients' $\mathrm{T}$ cells following in vitro stimulation with antiCD3/anti-CD28 may have resulted from exhaustion of their in vivo-activated T cells.

The current study by Bacchetta et al. (22) should spur investigators to analyze in detail the number and function of Tregs in IPEX patients. In addition, introduction of human FOXP3 mutations in mice that correspond to mutations that cause IPEX provides a useful strategy to investigate the relationship between FOXP3 expression and Treg development and function and to define the function of FOXP3 domains. It will also be important to search for proteins that interact with FOXP3, as mutations in the genes that encode for FOXP3 partners may underlie the IPEX-like phenotype in patients who lack detectable mutations in the FOXP3 gene.

Address correspondence to: Raif Geha, Karp Building, Division of Immunology, Children's Hospital, 1 Blackfan Circle, Boston, Massachusetts 02115, USA. Phone: (617) 919-2482; Fax: (617) 730-0528; E-mail: raif.geha@childrens.harvard.edu.

1. Dejaco, C., Duftner, C., Grubeck-Loebenstein, B., and Schirmer, M. 2006. Imbalance of regulatory T cells in human autoimmune diseases. Immunology. 117:289-300

2. Sakaguchi, S., Sakaguchi, N., Asano, M., Itoh, M., and Toda, M. 1995. Immunologic self-tolerance maintained by activated T cells expressing IL-2 receptor alpha-chains (CD25). Breakdown of a single mechanism of self-tolerance causes various autoimmune diseases. J. Immunol. 155:1151-1164.

3. Sullivan, K.E., McDonald-McGinn, D., and Zackai, E.H. 2002. CD4(+) CD25(+) T-cell production in healthy humans and in patients with thymic hypoplasia. Clin. Diagn. Lab. Immunol. 9:1129-1131.

4. Bensinger, S.J., Bandeira, A., Jordan, M.S., Caton, A.J., and Laufer, T.M. 2001. Major histocompatibility complex class II-positive cortical epithelium mediates the selection of CD4(+)25(+) immunoregulatory T cells. J. Exp. Med. 194:427-438.

5. Fontenot, J.D., and Rudensky, A.Y. 2005. A well adapted regulatory contrivance: regulatory $\mathrm{T}$ cell development and the forkhead family transcription factor Foxp3. Nat. Immunol. 6:331-337.

6. Fontenot, J.D., Rasmussen, J.P., Gavin, M.A., and Rudensky, A.Y. 2005. A function for interleukin 2 in Foxp3-expressing regulatory T cells. Nat. Immunol. 6:1142-1151.

7. D'Cruz, L.M., and Klein, L. 2005. Development and function of agonist-induced $\mathrm{CD} 25+\mathrm{Foxp} 3+$ regulatory $\mathrm{T}$ cells in the absence of interleukin 2 signaling. Nat. Immunol. 6:1152-1159.

8. Hori, S., Nomura, T., and Sakaguchi, S. 2003. Control of regulatory $\mathrm{T}$ cell development by the transcription factor Foxp3. Science. 299:1057-1061.

9. Fontenot, J.D., Gavin, M.A., and Rudensky, A.Y. 2003. Foxp3 programs the development and function of CD4+CD25+ regulatory T cells. Nat. Immunol. 4:330-336.

10. Fontenot, J.D., et al. 2005. Regulatory T cell lineage specification by the forkhead transcription factor foxp3. Immunity. 22:329-341. 
11. Ziegler, S.F. 2006. FOXP3: of mice and men. Annu. Rev. Immunol. 24:209-226.

12. Allan, S.E., et al. 2005. The role of 2 FOXP3 isoforms in the generation of human $\mathrm{CD}^{+}$ Tregs. J. Clin. Invest. 115:3276-3284. doi:10.1172/ JCI24685

13. Walker, M.R., et al. 2003. Induction of FoxP3 and acquisition of $\mathrm{T}$ regulatory activity by stimulated human $\mathrm{CD}^{+} \mathrm{CD} 25^{-} \mathrm{T}$ cells. J. Clin. Invest. 112:1437-1443. doi:10.1172/JCI200319441.

14. Thornton, A.M., and Shevach, E.M. 1998. CD4+CD25+ immunoregulatory $\mathrm{T}$ cells suppress polyclonal $\mathrm{T}$ cell activation in vitro by inhibiting interleukin 2 production. J. Exp. Med. 188:287-296.

15. Von Boehmer, H. 2005. Mechanisms of suppression by suppressor T cells. Nat. Immunol. 6:338-344.

16. Brunkow, M.E., et al. 2001. Disruption of a new forkhead/winged-helix protein, scurfin, results in the fatal lymphoproliferative disorder of the scurfy mouse. Nat. Genet. 27:68-73.

17. Lyon, M.F., Peters, J., Glenister, P.H., Ball, S., and Wright, E. 1990. The scurfy mouse mutant has previously unrecognized hematological abnormalities and resembles Wiskott-Aldrich syndrome. Proc. Natl. Acad. Sci. U. S. A. 87:2433-2437.

18. Clark, L.B., et al. 1999. Cellular and molecular characterization of the scurfy mouse mutant. J. Immunol. 162:2546-2554.

19. Wildin, R.S., et al. 2001. X-linked neonatal diabetes mellitus, enteropathy and endocrinopathy syndrome is the human equivalent of mouse scurfy. Nat. Genet. 27:18-20.

20. Bennett, C.L., et al. 2001. The immune dysregulation, polyendocrinopathy, enteropathy, X-linked syndrome (IPEX) is caused by mutations of FOXP3. Nat. Genet. 27:20-21.

21. Chatila, T.A., et al. 2000. JM2, encoding a fork head-related protein, is mutated in X-linked autoimmunity-allergic disregulation syndrome. J. Clin. Invest. 106:R75-R81.

22. Bacchetta, R., et al. 2006. Defective regulatory and effector $\mathrm{T}$ cell functions in patients with FOXP3 mutations. J. Clin. Invest. 116:1713-1722. doi:10.1172/JCI25112.

23. Lin, W., et al. 2005. Allergic dysregulation and hyperimmunoglobulinemia $\mathrm{E}$ in Foxp3 mutant mice. J. Allergy Clin. Immunol. 116:1106-1115.

24. Schubert, L.A., Jeffery, E., Zhang, Y., Ramsdell, F., and Ziegler, S.F. 2001. Scurfin (FOXP3) acts as a repressor of transcription and regulates $\mathrm{T}$ cell activation. J. Biol. Chem. 276:37672-37679.

\title{
Of mice, men, and elephants: Mycobacterium tuberculosis cell envelope lipids and pathogenesis
}

\author{
Lee W. Riley
}

\author{
Division of Infectious Diseases, School of Public Health, University of California, Berkeley, California, USA.
}

\begin{abstract}
Mycolic acids and structures attached to them constitute a major part of the protective envelope of Mycobacterium tuberculosis, and for this reason, their role in tuberculosis pathogenesis has been extensively studied. In this issue of the JCI, Rao et al. examine the effect of trans-cyclopropanation of oxygenated mycolic acids attached to trehalose dimycolate (TDM) on the murine immune response to infection (see the related article beginning on page 1660). Surprisingly, they found that an M. tuberculosis mutant lacking trans-cyclopropane rings was hypervirulent in mice. The recent recognition of a hypervirulence phenotype in mice associated with laboratory and clinical M. tuberculosis strains with altered cell wall components has provided new insights into how M. tuberculosis may establish persistent infection. However, to date, characterization of these bioactive products in pathogenesis has been largely reductionistic; the relationship of their effects observed in mice to the persistent infection and tuberculosis caused by M. tuberculosis observed in humans remains obscure.
\end{abstract}

The report by Rao et al. in this issue of the JCI (1) represents the latest chapter in a long history of studies examining the role of Mycobacterium tuberculosis bioactive cell envelope lipids in tuberculosis pathogenesis. To be sure, this history goes back more than 50 years, when Middlebrook et al. redescribed a characteristic broth-growth morphology (first described by Robert Koch in 1884) called cording associated with virulent tubercle bacilli (2). Subsequently, Hubert Bloch characterized the effect of petroleum ether-extractable "cord factor"

Nonstandard abbreviations used: $c m a A 2$, cyclopropane mycolic acid synthase 2; PGL, phenolic glycolipid; TDM, trehalose dimycolate.

Conflict of interest: The author has declared that no conflict of interest exists.

Citation for this article: J. Clin. Invest. 116:1475-1478 (2006). doi:10.1172/JCI28734. from $M$. tuberculosis on leukocyte migration and toxicity in mice (3). The toxicity in mice was demonstrated only after serial injections of the lipid extract, suggesting that the disease involved cell-mediated immunopathology (3). Ultimately, these effects of cord factor were traced to the glycolipid trehalose dimycolate (TDM) $(4,5)$. It later turned out that TDM is found in pathogenic as well as saprophytic mycobacteria (6). Recent studies suggest, however, that the relative composition and structural differences in TDM among different mycobacteria influence the host animal biologic response.

\section{Mycolic acids and their effect on host immune response}

TDM is composed of a nonreducing sugar trehalose covalently linked to mycolic acids.
Mycolic acids are $\beta$-hydroxyl fatty acids with an $\alpha$-alkyl side chain (7) (Figure 1). The M. tuberculosis cell wall contains 3 classes of mycolic acids: $\alpha$-, keto-, and methoxymycolates. $\alpha$-Mycolic acid has 2 cyclopropane rings, which are in the cis configuration (8, 9), while the keto- and methoxymycolates have 1 ring each in either cis or trans configuration (10). In addition to trehalose, mycolates are linked to arabinogalactan, which is covalently attached to the peptidoglycan layer (Figure 1) (11).

The relative composition of oxygenated mycolates influences the intramacrophage growth rate of $M$. tuberculosis (12). Strains lacking ketomycolates become reduced in their ability to grow inside THP-1 cells (12). Dubnau et al. reported that the absence of keto- and methoxymycolates leads to attenuation of $M$. tuberculosis in mice (13). Wild-type M. bovis strains possess a complete set of mycolic acids, but the vaccine strain $M$. bovis BCG-Pasteur lacks methoxymycolates (13). These observations indicate that differences in the relative composition of mycolates can influence the host immune response.

The report by Rao et al. goes further and shows that alteration in the trans-cyclopropane rings of mycolic acids in TDM affects the mouse immune response (1). They showed that a cyclopropane mycolic acid synthase 2 ( $c m a A 2)$ mutant of M. tuberculosis, which lacks trans-cyclopropane rings, is hypervirulent in mice. Accelerated mortality in mice was attributed to severe lung lesions 